\title{
Beyond podcasting: creative approaches to designing educational audio
}

\author{
Andrew Middleton* \\ Learning \& Teaching Institute, Sheffield Hallam University, Sheffield, UK
}

(Received 8 May 2008; final version received 3 April 2009)

\begin{abstract}
This paper discusses a university-wide pilot designed to encourage academics to creatively explore learner-centred applications for digital audio. Participation in the pilot was diverse in terms of technical competence, confidence and contextual requirements and there was little prior experience of working with digital audio. Many innovative approaches were taken to using audio in a blended context including student-generated vox pops, audio feedback models, audio conversations and task-setting. A podcast was central to the pilot itself, providing a common space for the 25 participants, who were also supported by materials in several other formats. An analysis of podcast interviews involving pilot participants provided the data informing this case study. This paper concludes that audio has the potential to promote academic creativity in engaging students through media intervention. However, institutional scalability is dependent upon the availability of suitable timely support mechanisms that can address the lack of technical confidence evident in many staff. If that is in place, audio can be widely adopted by anyone seeking to add a new layer of presence and connectivity through the use of voice.
\end{abstract}

Keywords: podcasting; digital audio; transformation; creativity; innovation

\section{Introduction}

Podcasting has only a limited value to education when it is understood from a simple technical perspective. For example, Deal $(2007,2)$ describes podcasting as "a means of publishing audio and video content on the web as a series of episodes with a common theme ... accompanied by a file called a 'feed' that allows listeners to subscribe to the series and receive new episodes automatically". However, when it is understood more broadly, driven by pedagogic requirements, a new, rich vein of educational applications for digital media emerges. Though only some of these may draw upon all of the technical characteristics of podcasting, many applications emerge for the use of voice in ways that can enrich the virtual learning environment (VLE).

This paper describes how academic staff responded to the installation of a VLE podcasting tool (Podcast LX) and the running of the Closer! pilot at Sheffield Hallam University, which was initiated to promote learner-centred approaches to a blended curriculum. Academics were asked to think beyond the connections that can be made between new technology and existing pedagogy to consider what new practice was afforded by podcasting. Proposals from the 25 self-selected academics showed a

\footnotetext{
*Email: a.j.middleton@shu.ac.uk
} 
desire to make the VLE a more human space through the greater use of voice. This was reflected in the name of the year-long pilot itself - 'Closer!'

This human concern contrasts with technical descriptions of educational podcasting, which often emphasise how the XML feed can enhance user access, and how it supports the serialisation of commonly themed content.

This paper reports on how a range of staff chose to enhance their practice with digital audio in the pilot.

\section{Background}

Podcasting is a technical term that describes the automatic distribution of asynchronous digital media to niche groups of subscribers using an RSS feed (RSS Advisory Board 2005). As such, it does not have any inherent educational value (Deal 2007). However, the capacity to capture and share learning voices, the flexibility it affords in providing access to media, its methods of production and its means of targeted distribution, do offer new opportunities to educators.

Disappointingly, the term is synonymous in some quarters with the transmission of the teacher's knowledge through the distribution of recorded lectures. A number of studies have attempted to evaluate podcasting, understanding podcasting in this simple way (e.g. Abt and Barry 2007; Lazzari 2009). Such studies assume that podcasting's value lies in its capacity to reproduce existing teacher-centred models through 'coursecasting' - the practice of recording and distributing lectures (Jones 2006; Kadel 2006). It should be noted that coursecasting has some benefits (Brittain et al. 2006): obviating the need for students to take notes in class resulting in more attention being paid to the teacher; providing the lecture for those who did not attend; providing a record to support revision (Evans 2008).

The availability of proprietary lecture recording tools and the development of iTunes $U$ (Apple Education 2008) might imply that teaching can be commoditised as an educational experience in which listening equates to learning, but this notion is challenged by Draper and Maguire $(2007,51)$ and others who recognise that lectures exist for "a particular group of learners, at a particular moment" and resist the suggestion that they can be "canned" for posterity. Coursecasting conflicts with progressive and increasingly dominant learning theories such as Social Constructivism (Vygotsky 1978), Communal Constructivism (Holmes et al. 2001) and Connectivism (Siemens 2005), which advocate richer, active learning experiences for learners, where learners are encouraged to arrive at personal understandings within a social context.

Podcasting is much more complex than coursecasting evaluation studies might suggest. As with any learning technology, its application is inevitably determined by many local factors that make the transferability of findings difficult (Kirkwood 2003) and some of the contexts that may affect the implementation of podcasting include: profile and size of student user groups; technical competence and confidence of all stakeholders; the intricacies of the institutional technical infrastructure and associated policies; teaching philosophies; professional philosophies; academic style; positioning of the resource in the pedagogy; learner awareness, motivation and preferences.

At the same time, and despite some of the initial interest in podcasting's mobile interface to learning (Campbell 2005), the use of the term is increasingly simplified to mean the online distribution of any asynchronous digital media, not just media 
distributed through RSS podcast feeds (Ralph et al. 2008). For example, France and Ribchester (2008) describe their use of personalised audio feedback as podcasting. Even where there is a feed, students tend to access podcasts directly from course sites using a PC, rather than via a feed or by using mobile devices (Malan 2007; Newnham and Miller 2007), whilst Aliotta et al. (2008) describe delivering podcasts during face-to-face teaching sessions.

In exploring the educational potential of podcasting we cannot assume that students want to learn with podcasting simply because they belong to the 'Google Generation' (CIBER 2008, 5). Undoubtedly, some students own devices capable of managing podcast subscriptions, but if they are aware of the technical processes at all, they often perceive it as an advanced technology and one that they do not associate with studying or with the use of their personal equipment (Cann 2007; Lee and Chan 2007).

However, the proliferation of MP3 players and the frequent mention of iPods and podcasting in the popular media have been useful in raising awareness of digital media amongst academics, perhaps suggesting that it is becoming reliable, enjoyable and engaging for users (Campbell 2005). Similarly, and importantly, the popularity of user-generated video websites like YouTube, suggest that digital media is no longer the preserve of media technicians (Cann 2007).

Many authors (e.g. Aliotta et al. 2008; Cane and Cashmore 2008; Chan and Lee 2005; Draper and Maguire 2007; Lazzari 2009; Stewart and Doolan 2008) have shown that digital media technology can have myriad engaging and active learning applications. This variety reflects the variety of challenges and interests facing the teachers and students who have explored it.

Other commentators suggest podcasts are best when they: are brief (Chan and Lee 2005); allow academics to offer pre-vision and re-vision materials to lectures (Aliotta et al. 2008; Nortcliffe and Middleton 2008); are used to summarise knowledge (Cane and Cashmore 2008; Evans 2008; Ralph et al. 2008), especially when it is the students who are producing the summaries (Draper and Maguire 2007).

The initiative discussed here, however, was informed by the belief that new and emerging technologies should be explored to enable new and emerging learnercentred pedagogies, enabling approaches that have, until now, not been realistically accessible. Learner-centredness describes pedagogy that places "student responsibility and activity at its heart, in contrast to a strong emphasis on teacher control and coverage of academic content in much conventional, didactic teaching" (Cannon and Newble 2000, 16). Others have recognised the opportunity to incorporate audio as a component in this learning mix: Lee, McLoughlin and Chan (2007) consider how audio can be used as a catalyst in mediating knowledge creation where learners have been involved in generating digital audio learning objects (DALOs); Stewart and Doolan (2008) continue to explore how audio can be used to promote self-reflection and collaborative learning.

The Closer! pilot is part of an ongoing exploration of digital audio-enhanced pedagogy. The DALO concept (Middleton and McCarter 2005; Lee, McLoughlin, and Chan 2007) proposes that the collaborative design of short audio learning objects can provide a valuable learning focus.

Similarly the concept of media intervention (Middleton 2008; Middleton and Mather 2008) suggests that digital media should be considered, not as a didactic tool, but as a simple catalyst to promote learner activity, setting challenges, seeding ideas, illustrating problems or 'getting students in the zone'. 


\section{Establishing the pilot}

The Closer! pilot was managed from a central educational development unit, its name emphasising how the virtual proximity of learning voices offers a new sense of presence to the VLE.

Educational podcasting awareness workshops were run for academics in each faculty and the main characteristics of the technology were highlighted. The workshops emphasised the many ways in which podcasting can support learning, where students can be either users or producers of the media. Ideas for creative educational podcasting were discussed. Subsequently, 25 workshop participants joined the one-year pilot on a voluntary basis. The aim of the pilot was to encourage academic innovation in the use of digital media to enhance learning, teaching and assessment.

All but one set of participants set out to use audio in the pilot, with a team from Nursing exploring the potential of video podcasts for a clinical skills module.

A community site was established in the VLE for pilot participants. This linked to a collection of support materials targeted at staff and students. These included PDF guidance documents, media design templates, demonstration screencasts and an extensive FAQ (Frequently Asked Questions) collection. They covered the practicalities of working with audio hardware, software and the Podcast $L X$ tool; the pedagogic flexibility offered by the technology; and presented visualisations of the processes.

Specific workshops about using the technology were not run prior to the pilot; the awareness workshops had demonstrated the accessibility of the technology. However, institutional and faculty-based support teams were alerted to expect requests for help and equipment.

A series of weekly 'Idea Announcements' were posted to the VLE intended to inspire the participants initially, and latterly to provide ideas for future development. These ideas (see Table 1) were kept brief and open-ended with participants being encouraged to adapt them to suit their needs.

The pilot's podcast was designed as a communal constructivist device (Holmes et al. 2001) and could be accessed directly through Blackboard or via a feed. It also modelled a relaxed semi-formal style, realistic production values and an example of how episodes could be embedded within the VLE using the Podcast $L X$ tool. Editing was kept to minimum, exemplifying the light touch approach to sustainable educational production. 'Show notes' accompanying each interview provided a listening menu, indicating the timing of various themes in the conversation making navigation of the recordings easier. Audio messages were occasionally distributed via the podcast informing participants of events, reminding them of support and inviting them to come forward for interview.

The pilot presented a research opportunity to explore the versatility of audio as an educational medium as evidenced in the methods devised by academics in their many contexts. Given the interest and willingness of pilot participants to look beyond coursecasting and other teacher-centred approaches, the following research question was used to frame the investigation:

How did academic staff in a UK university apply their emerging understanding of educational podcasting as a medium to engage their students?

\section{Research methodology}

Pilot participants were encouraged to report back after about two months to the pilot community through interviews for the Closer! podcast. Participants had the opportunity 
Table 1. Examples of idea announcements for educational podcasting from the Closer! pilot VLE.

\begin{tabular}{ll}
\hline Audio Glossary & $\begin{array}{c}\text { A glossary of complex ideas or jargon, created by students and/or } \\
\text { tutors }\end{array}$ \\
Professional briefings & $\begin{array}{c}\text { Getting professionals into the University can be difficult to } \\
\text { organise, however asking someone out in the "real world' to } \\
\text { brief your student assignment can set an authentic, professional } \\
\text { tone. It can be a lot easier to organise an audio recording. There } \\
\text { are several options, and some make it easy for them to stay } \\
\text { involved with the assignment along the way: ask them to record } \\
\text { audio briefings from their office; use internet telephony to make } \\
\text { recordings; or invite them in and use an MP3 recorder in your } \\
\text { office to record their message. } \\
\text { Broadcast news programmes, and the various techniques they use } \\
\text { (e.g. “...And Finally") offer a good framework for student } \\
\text { podcasts because they consider various perspectives and should } \\
\text { be non-judgemental. Students and their audience will be } \\
\text { familiar with the genre and so producers have useful reference } \\
\text { points when beginning to plan what they will do. When setting } \\
\text { a student podcast, therefore, consider telling your students, "Do } \\
\text { it in the style of a } 2 \text { minute news bulletin that incorporates at } \\
\text { least two contrasting perspectives." } \\
\text { Listening to or making podcasts can be done anywhere given the } \\
\text { portable devices and services we can access. If you and/or your } \\
\text { students are going off-campus, capture the intensity and } \\
\text { richness of the trip on audio: interviews with people you } \\
\text { encounter; data collection; reflective discussions on location; } \\
\text { observation; sound stories. }\end{array}$ \\
Field Assignments & \\
\hline
\end{tabular}

to meet in person at the outset of the project in the workshops and drop-in support sessions, but otherwise did not meet as a project group. Nine of the 25 participants volunteered to share their experience, in turn, over a period of eight weeks. Of the others, some were not available, some were reticent to talk about their progress publicly and the remainder did not begin podcasting until the second semester.

The research draws upon these nine semi-structured interviews. The interview process provided participants with a timely opportunity for reflection, as well as with an opportunity to inform the plans of other participants preparing for second semester modules.

The research methods used were intended to directly affect the design of podcast applications in the ongoing pilot, as well as informing the research. The approach is typical of action research methodology, with the research intervention not only informing and affecting listening participants, but the interviewees too. As such, the method is "a socially engaged approach to knowledge generation ... adopt[ing] a dynamic, cyclical process which moves through phases of planning, action, observation and reflection" (Bloor and Wood 2006, 10). As with other action research methods, the intention was that the community of participants would be empowered through its collaborative involvement (Cohen, Manion, and Morrison 2000, 79).

The interviews were conducted and analysed by the author, who also managed the pilot. However, the data should be understood primarily as artefacts of pilot activity and not as post hoc participant reflection upon it.

The questions used to frame the interviews were: 
(1) What do/did you hope to achieve?

(2) What ideas have you had?

(3) What have you actually done?

(4) How have you and your students managed?

(5) What have been the important characteristics of the technology for you?

The interviews were transcribed and analysed by the author. The transcripts were coded according to the questions and six themes emerged:

(1) The value of the RSS feed in the academic context;

(2) Podcasting and pedagogic change;

(3) Media intervention;

(4) Scalability;

(5) Technical competence and confidence;

(6) Tutor strategies for implementing podcasting.

Each theme was evident in most interviews, though not necessarily common to all.

\section{Project stories and emerging themes}

Outline descriptions of nine project stories from the Closer! pilot are presented in Table 2.

\section{The value of the RSS feed in the academic context}

The topic of the podcast feed was not discussed by everyone. Those who did discuss it reported that they did not push it. "I only did that part of it for me to make sure that I could do it". (S2) The consensus was that:

They're going to the VLE. They want to listen to the audio while they're doing their work. So subscribing to the podcast is meaningless to them as they want it while they're working. (S4)

One academic (S3) cautioned that it is not appropriate to use these technologies unless the students:

... can see clearly that it's got a real purpose ... What they're saying to me is, "Our time isn't limitless either ... If there's a benefit we'll go with you and we'll do it". I suppose we haven't got to that level of thinking about it really. Our longer term aim is to make the Blackboard sites more alive.

\section{Podcasting and pedagogic change}

In Nursing (S1) the existing classroom practice was proving difficult to scale with increasingly large cohorts. Video learning objects were introduced to allow students to review techniques and develop their confidence before going onto the hospital wards, "where this is happening to a real patient". The tutors were also interested in extending the learning environment through the use of portable devices into the students' hospital practice. 
Table 2. Closer! pilot project stories.

\begin{tabular}{|c|c|}
\hline Story 1 (S1) & $\begin{array}{l}\text { Nursing staff and students produced video learning objects about clinical } \\
\text { techniques, supporting the transition of placement students from the } \\
\text { safety of the clinical skills classroom to ward-based practice. }\end{array}$ \\
\hline Story 1 (S2) & $\begin{array}{l}\text { Sport student groups produced DALOs on key topics based upon a } \\
\text { research activity initially written up in group wikis. Students then } \\
\text { independently critically reviewed all of the audio objects in the shared } \\
\text { module resource and fed back to peers. The module tutor set out to } \\
\text { encourage the social construction, synthesis, and self-assessment of } \\
\text { knowledge. He later provided audio feedback to the cohort on the } \\
\text { assignment. }\end{array}$ \\
\hline Story 3 (S3) & $\begin{array}{l}\text { In Business several approaches were used including: the setting of a } \\
\text { weekly activity using audio announcements; the student submission of } \\
\text { audio sources from relevant global podcasts to add to the module feed; } \\
\text { episodes about placement preparation edited by the tutor from } \\
\text { interviews with students on international placement. The tutor's } \\
\text { intention was to raise engagement by making the presentation of } \\
\text { material on the Blackboard site more interesting and to make } \\
\text { connections to the outside world. }\end{array}$ \\
\hline Story 4 (S4) & $\begin{array}{l}\text { The Software Engineering tutor took an audio scaffolding approach with } \\
\text { ongoing audio feedback for students working through the process of } \\
\text { applying for jobs. Feedback notes given in weekly classes on common } \\
\text { areas of weakness were recorded and redistributed through the VLE. } \\
\text { The audio provision was intended to add impact to the feedback } \\
\text { messages and ensure that the students could access tutor advice in a } \\
\text { timely way whenever they returned to the task. }\end{array}$ \\
\hline Story 5 (S5) & $\begin{array}{l}\text { In Art \& Design semi-structured conversations were recorded on the } \\
\text { "questions you're afraid to ask." These were initially targeted at } \\
\text { students with dyslexia. Episodes featured discussions on topics such as, } \\
\text { "What is a quote?", "What is academic writing?", "What's the } \\
\text { difference between qualitative and quantitative research?" so } \\
\text { addressing fundamental questions that students rarely ask, but should. }\end{array}$ \\
\hline Story 6 (S6) & $\begin{array}{l}\text { In Computing two approaches were used: Students submitted links to } \\
\text { audio podcasts published elsewhere; students were offered podcast } \\
\text { production as a presentation option on a research assignment as an } \\
\text { alternative to an essay or a face-to-face presentation. } \\
\text { In both cases the intention was to inform discussion about, and } \\
\text { subsequently affect, the presentation of their own module. }\end{array}$ \\
\hline Story 7 (S7) & $\begin{array}{l}\text { In Journalism there were two student podcasting assignments. } \\
\text { Students were required to work independently carrying out vox pops ("an } \\
\text { essential journalism technique") with a range of people on the topic, } \\
\text { "What makes a good student?" } \\
\text { Later, groups were asked to create a short feature on why you should } \\
\text { study Journalism at the university as a marketing device. } \\
\text { These techniques were intended to replace an existing study skills module } \\
\text { with a more authentic pedagogy. }\end{array}$ \\
\hline Story 8* (S8) & $\begin{array}{l}\text { In Communications the intention was to develop an audio library of short, } \\
\text { reusable, impromptu responses to questions submitted by post-graduate } \\
\text { students on a distance learning course. This library was intended to } \\
\text { break down their sense of isolation by introducing voice to the VLE. }\end{array}$ \\
\hline Story 9* (S9) & $\begin{array}{l}\text { A Health Policy podcast featuring the voices of global experts was seen } \\
\text { to be valuable for many in the Health faculty as it offered flexible } \\
\text { access to different inter-professional perspectives. }\end{array}$ \\
\hline
\end{tabular}

*Stories 8 and 9 had not produced their podcasts at the time of the interviews. 
In Sport (S2) student-generated group audio pieces replaced group presentations. The tutor's intention was to raise student motivation by creating a sense of responsibility amongst student groups who were charged with developing a common module repository. Creating a sense of student purpose was a driver in S3 too where the academic noted that:

Trying to get some of the students to engage and do the work in the group discussions - a lot of it falls flat. And it's difficult then. Sometimes it's like trying to get blood out of a stone. But they like doing things.

The Software Engineering tutor (S4) was keen to pursue the use of audio to aid reflective practice. As a result of her own use of audio she intends to, "throw responsibility back at the students to record reflective logs of their lab work".

The approach taken in Journalism radically changed the study skills module from a key module that was not enjoyed by either staff or students, to one where students became actively engaged in a more authentic activity that brought key skills right back into focus.

\section{Media intervention}

The media intervention concept proposes that learning with media can initiate and facilitate learning. The Sports tutor valued the role that media could play when used simply:

It was about the 'students as producers' thing, it is by actually doing this. That is where the learning comes.

In Software Engineering the immediacy of the medium was appreciated. Timely interventions through broadcast audio feedback kept the students on track whenever they were ready to re-engage with the ongoing task through the reiteration of key points. The immediacy and currency of digital media was also appreciated in Nursing (S1) where the notion of expertise "changes regularly".

Again, the timeliness provided by asynchronous digital media allowed students to engage with the Art \& Design audio conversations (S5):

Often you don't need that material until you're at the point of needing it.

Intervention by voice was an attractive option to the Business tutor who valued the new opportunity to engage students more personally in the VLE. She wanted to:

... bring in the voice element to try and engage the students to try and make them do activities in preparation for say their tutorial, but also as a way of us being able to update the materials as different things happen and occur in the outside world. It's a friendlier atmosphere because there's somebody talking to them rather than just a cold text. (S3)

In Computing (S6) the tutor reported that media resulted in a deeper engagement:

They'd not only found audio pieces but other stuff that was supportive, such as screencasts.

This got a bit of discussion going on the discussion board. 


\section{Scalability}

The pilot was, in part, interested in the scalability of the user production of media. Expectations for high quality, broadcast standard production were challenged. An important message in the workshops, concerning production values, had been, "We are not the BBC, we are academics and students". Despite this several participants did not want to appear 'too amateurish'. "If it's not of a good quality students are not going to respect this", one explained. However, others recognised that they were not interested in the production quality of student work:

I made it clear that I wasn't marking on the quality of the product but that what I was looking for was a variety of responses and a variety of voices. (S7)

The danger is that expectations for high quality from either staff or students will impede production and scalability.

The assessing of student work impacts on the scalability of audio models. Reviewing 60 pieces of student work, even when they only last 45 seconds each, is a significant task:

I lost the will to live at one point! I think we asked for 45 seconds for the first piece and a couple of minutes for the group piece because I felt the group piece should have a bit more work in it. I think 45 seconds was just about right. (S6)

Peer review is one approach that works as long as expectations and guidance are clear: "I think the methodology I was using could be transferred to any topic" (S2).

In student-producer models, such as (S7), scalability is affected by the access to equipment and most importantly by the confidence of each student in using it. This connects directly to a fifth theme.

\section{Technical competence and confidence}

Several of the respondents noted that there was a small initial technology hurdle to overcome, but that podcasting could be "picked up very quickly" (S1). Similarly the Computing tutor noted:

I could go to Audacity [recording software] and I could record very easily and quickly - probably quicker than drafting it out in text ... I think it's a confidence thing with the more you try and do things like this the easier it becomes to just do it. I think if you think about it too much and plan it out and script it, that can sometimes make it a little more difficult than just going for it.

This illustrates the tutor's confidence with technology and an existing strategy for developing new skills. However, most participants had not produced digital media before and the technology hurdle was significant for them. Many were nervous, became frustrated or did not have a personal strategy for learning to use new technology. In some cases they avoided it altogether. Even where they were expecting students to be the producers, they felt that they needed to be fully conversant with the technology. The Journalism tutor (S7) reported that she "felt very frustrated in that students were coming to me with questions that I wasn't able to answer immediately".

Many of the tutors were deterred from taking part at all. Some reported that they had other pressures that prevented them from staying involved in the pilot: 
When it came to do it I didn't know enough about podcasting myself and I felt I needed to develop the skills to support students, because I couldn't really expect them to do this if I wasn't sufficiently comfortable with the technology myself. So in the end I didn't do it ... I would have to do them at home and my computer is a bit ancient, so I didn't really want to try this. (S8)

Even though there was an abundance of support material in various formats available to participants, the interviews revealed that many of the academics expected to become fluent in using the various technologies and that this would require more personal support and time:

I just want more time to learn the technology. The barriers to doing more are having the time to learn and become fully confident with the technology. (S5)

Expectations of developing professional technical skills and aspiration to professional production values resulted in over-planning in at least one case (S9). This ambition resulted in an insurmountable obstacle:

We invited people to a meeting and set up a Blackboard site and the idea was that through the Blackboard site that we'd have a series of discussions and the podcasts would be part of that. Frankly, since we did that it started well, but we have become extremely busy.

There was a lack of competence and confidence amongst students too. Most students are not conversant with digital media production:

I'd also assumed that the students would be more technically skilled than I am and that's not necessarily the case. And that they would be more confident around technology than I am and in practice, God help them, they're even worse off than I am. (S7)

One academic (S8) realised that her distant students would be preoccupied in the first semester module with learning how to use university facilities remotely and that she needed to make their learning more manageable:

Looking at podcasting in the second module might be better, [to avoid] overloading the students.

\section{Tutor strategies for implementing podcasting}

Despite the hurdles encountered by some academics, most were eventually successful in seeing their ideas through by employing various strategies:

We put ourselves under pressure, but that made it happen. (S1)

My strategy for getting through was making the mistake of putting it on the module guide that we were going to do it! (S7)

I spoke to a colleague who is more au fait with those sorts of things than I am and he delivered a couple of sessions on using Audacity ... I sat in with the students and was able to do [the activities] reasonably competently. (S7)

There was little evidence that the support materials had been used: 
I don't want a manual that I've got to work through ... I'm like that about a lot of the digital changes that are happening. (S5)

Unless you look at things before the teaching starts, it's very much a hand-to-mouth existence. I just don't get the time to go through things as much as I'd like. (S7)

Amongst the staff interviewed, those who did not succeed initially with the technology stayed motivated and subsequently found colleagues to help them learn or attended training. The Communications lecturer, who had not succeeded during the pilot, subsequently reported back to others via the pilot podcast on an audio skills workshop she had attended through a recording she made independently.

\section{Conclusion}

This paper has considered the versatility of audio as an educational medium through the experience of academic staff in a pilot initiative. The research aimed to discover how academic staff applied their understanding of educational podcasting as a medium to engage their students. A review of the literature and the experience of staff in the Closer! pilot has resulted in several conclusions.

Though the use of the term podcasting by the media and the availability of suitable tools in the institutional VLE have led to greater interest amongst some academics, the RSS model of distribution is not regarded as useful by most academics. Instead, staff expected their students to come to the VLE to use the media.

Academics in the pilot enjoyed the opportunity to creatively consider how audio could be used to enhance their teaching. Audio provided them with a mechanism to move towards learner-centred pedagogies, often in ways that positioned media as a catalyst in encouraging student activity.

Audio also demonstrated a capacity to facilitate authentic engagement, allowing students to connect in various ways to the outside world, both as listeners and publishers. The ease and speed with which digital audio can be deployed was used to support timely interventions and in some cases promoted information currency and responsiveness.

However, the project stories show that academics can be held back by several factors, even when podcasting is subsequently found to be relatively simple to do. These include ongoing commitments, a lack of technical learning strategy and a lack of confidence in using unfamiliar media technology. There was a tangible sense of risk in the pilot that deterred some from participating. It is critical, therefore, that support in using digital media is available for some academics whenever the need occurs, though this need not be extensive or protracted. The institutional scalability of educational podcasting will be hindered where technical confidence is lacking. Peer mentoring, amongst staff or students, can help. However, it was also noticed that confidence is developed through quick and simple successes given that unfamiliarity is the major hurdle to overcome.

It appears that there is a diverse range of confidence amongst students too; it would be wrong to assume their prior experience with, or interest in, digital media or its production. Nevertheless, student podcast production offered an engaging exercise where it was used.

Assessment of time-based media products can be time consuming. Peer assessment can help and the assessment of the student learning process can be more useful and realistic than assessment of their products. 
Findings from the pilot and related digital media initiatives have resulted in an evaluation of the institution's infrastructural capacity to support digital media-based pedagogy. Low risk methods designed to familiarise staff with using digital media have been devised, providing subject teams with the opportunity to touch and discuss the technology.

Historically digital media may have been the preserve of the learning technologist, but evidence from the pilot and initiatives elsewhere indicates that audio, if introduced with care, can be widely adopted across the curriculum.

The use of voice in the VLE is softening some of the more formal, hard edges created by the dominance of text-based materials so far, bringing a sense of personal presence and connectivity to the space. Pedagogic innovation involving audio will continue to contribute to the VLE becoming a more vibrant and diverse learning space.

\section{References}

Abt, G., and T. Barry. 2007. The quantitative effect of students using podcasts in a first year undergraduate exercise physiology module. Bioscience Education e-Journal 10: $8-10$.

Aliotta, M., S. Bates, K. Brunton, and A. Stevens. 2008. Podcasts and lectures. In Podcasting for learning in universities, ed. G. Salmon and P. Edirisingha, 33-42. Milton Keynes, UK: Open University Press.

Apple Education. 2008. iTunes $U$ and mobile learning. Apple website. http://www.apple.com/ education/itunesu_mobilelearning/itunesu.html

Bloor, M., and F. Wood. 2006. Keywords in qualitative methods: A vocabulary of research concepts. London: Sage.

Brittain, S., P. Glowacki, J. Van Ittersum, and L. Johnson. 2006. Podcasting lectures. Educause Quarterly 3: 24-31.

Campbell, G. 2005. There's something in the air: Podcasting in education. Educause Review November/December: 32-46.

Cane, C., and A. Cashmore. 2008. Student-produced podcasts as learning tools. Paper presented at the Higher Education Academy's fourth Annual Conference July 1-3, at the Harrogate International Centre.

Cann, A.J. 2007. Podcasting is dead. Long live video! Bioscience Education e-Journal 10.

Cannon, R., and D. Newble. 2000. A guide to improving teaching methods: A handbook for teachers in university and colleges. London: Kogan Page.

Chan, A., and M.J.W. Lee. 2005. An MP3 a day keeps the worries away: Exploring the use of podcasting to address preconceptions and alleviate pre-class anxiety amongst undergraduate information technology students. In Good practice in practice. Proceedings of the Student Experience Conference, ed. D.H.R. Spennemann and L. Burr, 59-71. Wagga Wagga, NSW: Charles Sturt University.

CIBER. 2008. Information behaviour of the researcher of the future: CIBER briefing paper. http://www.jisc.ac.uk/media/documents/programmes/reppres/gg_final_keynote_ 11012008.pdf

Cohen, L., L. Manion, and K. Morrison. 2000. Research methods in education. 5th ed. London and New York: RoutledgeFalmer.

Deal, A. 2007. Podcasting - a teaching with technology white paper. Pittsburgh, PA: Carnegie Mellon University.

Draper, S.W., and J. Maguire. 2007. Exploring podcasting as part of campus-based teaching. Practice and Evidence of Scholarship of Teaching and Learning in Higher Education. 2, no. 1: 42-63.

Evans, C. 2008. The effectiveness of m-learning in the form of podcast revision lectures in HE. Computers \& Education 50: 491-8.

France, D., and C. Ribchester. 2008. Podcasts and feedback. In Podcasting for learning in universities, ed. G. Salmon and P. Edirisingha, 33-42. Milton Keynes, UK: Open University Press. 
Holmes, B., B. Tangney, A. FitzGibbon, T. Savage, and S. Meehan. 2001. Communal Constructivism: Students constructing learning for as well as with others. In The proceedings of Society for Information Technology and Teacher Education International Conference 2001, ed. C. Crawford, 3114-9. Chesapeake, VA: AACE.

Jones, D. 2006. Enhancing the learning journey for distance education students in an introductory programming course. Central Queensland University. http://cq-pan.cqu.edu.au/ david-jones/Publications/Papers_and_Books/react1.pdf

Kadel, R. 2006. Coursecasting: The wave of the future? Leading and Learning with Teachnology 33, no. 5: 48-49. http://www.iste.org/Content/NavigationMenu/EducatorResources/ YourLearningJourney/EnvisioningtheFutureofEducationandTechnology/Coursecasting _ the_Wave_of_the_Future.pdf

Kirkwood, A. 2003. Understanding independent learners' use of media technologies. Open Learning 18: 155-75.

Lazzari, M. 2009. Creative use of podcasting in higher education and its effect on competitive agency. Computers \& Education 52, no. 1: 27-34.

Lee, M., and A. Chan. 2007. Pervasive, lifestyle-integrated mobile learning for distance learners: An analysis and unexpected results from a podcasting study. Open Learning: The Journal of Open and Distance Learning 22, no. 3: 201-18.

Lee, M., C. McLoughlin, and A. Chan. 2007. Knowledge creation processes of students as producers of audio learning objects. In Beyond control: Learning technology for the social network generation. Research proceedings of the 14th Association for Learning Technology Conference, ed. S. Wheeler and N. Whitton, 116-28.

Malan, D. 2007. Podcasting computer science E-1. In Proceedings of SIGCSE'07, March 7-10, 2007, Covington, Kentucky, USA, 389-93.

Middleton, A. 2008. Audio feedback: Timely media interventions. In Proceedings of The Third International Blended Learning Conference, 'Enhancing the Student Experience', University of Hertfordshire, UK, Wednesday 18th-Thursday 19th June 2008, ed. H.J. Millar and A.L. Jeffries, 15-27.

Middleton, A., and R. Mather. 2008. Machinima interventions: Innovative approaches to immersive virtual world curriculum integration. ALT-J Research in Learning Technology 16, no. 3 (Special Issue: Learning and teaching in virtual worlds): 207-20.

Middleton, A., and R, McCarter. 2005. Engaging solutions: A collaborative approach to digital audio learning object (DALO) production. Workshop presented at ALT-C 2005, Manchester, UK, September 6-8. http://www.alt.ac.uk/altc2005/timetable/files/515/ Engaging\%20solutions_v2.ppt

Newnham, L., and C. Miller. 2007. Student perceptions of podcasting to enhance learning and teaching in an information systems course. In Beyond control: Learning technology for the social network generation. Research proceedings of the 14th Association for Learning Technology Conference, ed. S. Wheeler and N. Whitton, 104-15.

Nortcliffe, A.L., and A. Middleton. 2008. Blending the engineer's learning environment through the use of audio. Journal of the Higher Education Academy Engineering Subject Centre 3, no. 2: 45-57.

Ralph, J., N. Head, S. Lightfoot, and E. Jubb. 2008. Pol-casting: The use of podcasting in the teaching and learning of Politics and International Relations. Paper presented at the Higher Education Academy's fourth Annual Conference, July 1-3, at the Harrogate International Centre.

RSS Advisory Board. 2005. Really Simple Syndication: RSS 2.0.10 Specification (revision published by the RSS Advisory Board on October 15, 2007). http://www.rssboard.org/ rss-2-0-1-rv-6

Siemens, G. 2005. Connectivism: A learning theory for a digital age. http://www.elearnspace.org/Articles/connectivism.htm

Stewart, W., and M.A. Doolan. 2008. Listen to this: Enhancing the learner experience through the use of audio within next generation technologies. Paper presented at the Higher Education Academy's fourth Annual Conference, July 1-3, at the Harrogate International Centre.

Vygotsky, L.S. 1978. Mind in society. Cambridge, MA: Harvard University Press. 